\title{
Regeneration through Design. Comparing old and new phases of urban renewal strategies.
}

\author{
Parente, Marina ${ }^{a}$; Sedini, Carla ${ }^{b} \&$ Simonelli, Giuliano ${ }^{c}$ \\ a Design Department - Politecnico di Milano, Italy. marina.parente@polimi.it, \\ b Design Department - Politecnico di Milano, Italy. sedini.carla@gmail.com, \\ c Design Department - Politecnico di Milano, Italy. giuliano.simonelli@polimi.it
}

\begin{abstract}
In the last years, a new phase of economic crisis, which is concerning sectors of manufacturing industries, is affecting Europe. Focusing on Italy, sectors which have strongly characterized our country, such as textile and accessories, are facing with a fluctuating period of crisis. Also in this case, as it happened from late '80s, the urban structures and identities are seriously affected and need interventions of regeneration in order to gain new life both from social, productive and commercial point of views. Having in mind the Italian case, while the first phase identified had the characteristics of a disruptive macro-phenomenon, the second phase is more subtle and gradual.
\end{abstract}

In this paper we are going to focus on changes of design culture in light of these urban phenomena. While we can already make a first evaluation of regeneration projects developed after the crisis of heavy industry sectors, the most recent events of industrial recession and the consequent regeneration of the correspondent empty areas are still ongoing.

In order to analyze and, where it is possible, compare these two phases, we are going to look at two Italian case studies. The first is Bicocca, an area of Milan, which in the '90s was interested by a massive plan of regeneration and transformation after the closure of Breda and Pirelli industries. The second is Biella, a Piedmont Province city, which has been one of the most important centers for the textile and wool industry; the crisis of this sector strongly emerged in the first years on 2000 even if it had already begun between '80s and '90s when the biggest textile factories closed down. The differences between these two examples are not merely physical and dimensional but are clearly influenced by a different timing in the regeneration processes, which occurred in these areas (or, in the case of Biella, is still occurring). The analysis proposed in this paper will be focus on the work of research developed within two didactic experiences.

Notwithstanding the distinctions in terms of objectives and actors involved, in this paper we are going to delineate a systemic approach to study and design for the regeneration, improvement and innovation of places. We will try to understand if, through strategic design, it is possible to identify those soft levers and interventions able to rejoin the pieces of places, which lost their functionality and identity.

Keywords: Strategic Design, Design Thinking, Design for Territories, Urban Regeneration 


\section{Introduction}

In this paper we are going to deal with the topic of brownfields regeneration looking at the role that design can have in these processes.

Starting from a review of the strategies put in place through different phases of industrial dismission, we will look at design approaches for (Parente, 2012):

- $\quad$ constructing new urban identities

- $\quad$ narrating and building local scenarios

- $\quad$ showing and communicating places

We are going to present a strategic design process developed in connection with the capabilities which design can exploit for the regeneration of urban areas. These approaches have been tested during several masters and higher education courses. In these pages we are going to present two specific case studies developed on real Italian contexts: Bicocca district in Milan and the city of Biella in the Piedmont Region.

Comparing the two cases both in terms of their positioning in the regeneration process timeline and of the strategies used, we are going to highlight the role of design for the "reconnection" of fragmented pieces, resulting from an already accomplished renovation (Bicocca), and for the start of a completely new phase of the regeneration process (Biella).

\section{The phenomenon of urban brownfields from the ' 90 s since today}

In the last years, a new phase of economic crisis is affecting Europe. Focusing on Italy, sectors which have strongly characterized our country, such as textile and accessories, are facing with a fluctuating period of crisis. As it happened from late ' $80 \mathrm{~s}$, the urban structures and identities are seriously compromised and they need interventions of regeneration in order to gain new life both from social, productive and commercial point of views. Having in mind the Italian case, while the first phase identified had the characteristics of a disruptive macro-phenomenon, the second phase is more subtle and gradual.

The first phase of the industrial dismission was a huge and devastating phenomenon not only from a socio-economic point of view but also from a cultural one. Suddenly, certainties about the urban development which run the "creation" of contemporary cities, were no longer valid. In those days, cities had to face with internal "scars" and huge empty areas, abandoned by their functions, their economies and their meanings. In 1990 Bernardo Secchi wrote that the scenarios which are recalled by the "dismission", the "decline", the "emptiness" are, only in some cases, tragic and hopeless, but more often are melancholic; only recently these scenarios have been opened to hope and chance. Secchi also declared that only after a long and uneasy consideration, we can take a critical distance from the polyedric system of situations and experiences that these scenarios are referring to, in order to give a first interpretation, using a more clear perspective.

A positive and constructive vision about the dismissed industrial areas is needed, because they are potential places where to foresee new urban scenarios and a more complex reflection on the whole city. Secchi also wrote that it is probably the right time to go on with projects which were not "demonstrative" and exemplar which were able to show the paths and their goals; in addition to that it is important to 
develop projects which did not match contrasting "fragments" to the existing city, but to elaborate more well defined projects which:

- really involve the city, its territories and its history;

- are able to collect the results of the past experimentations

- turn accomplishments into starting points for a new urban experience, for a new reflection on the living space.

This is what the majority of the reuse dismissed areas projects are not still able to express and desire.

At the same time, the discussion about the industrial heritage and about its tangible and intangible value is going on: "In the meanwhile we have to decide if these obsolete areas are today emptiness to be filled in with new contents or full spaces with contents to be, even only partially, conserved" (Rubino, 1996: p.119). This sentence clearly synthesize an initial bifurcation in the approach toward the dismissed areas in relation with the value given to the "leftovers", which we can sum up in two opposite visions (Parente, 2002):

- erase everything, rejecting the importance of the recent past:

○ to accomplish the return to a previous of (fake) not-artificial condition (for example the urban parks policy)

- to start a reconstruction urban process, projection of new desires (as in the case of Paris urban transformations, such as the Parc Citröen of 1992, where only the name was saved, or the Zac of Bercy 1988-92)

- preserve everything as it was, stuck in time:

$\circ$ according to a poetic taste for an abandoned scenario

○ pursuing a "death" refuse, the "renew" to seem unaltered (as in the case of Ironbridge e and of English open-air museums)

Between these two extremes, "non-intervention" versus "absolute change", it is possible to evaluate intermediate levels of conservative recovery, interpreting the conservation as a possible strategy for the memories transfer. The issue about the possible "ways" depends on the selection and the identification of what has to be transmitted. Then, it is difficult to identify, among the several memories of a postindustrial city, what can be the choosing criteria, as also Carlo Olmo stated:

"The problem is that each memory is relevant, because it shows a process, not a product: and the memory of a process is the hardest to be saved (...). Extrapolate a building and turning it into a museum of an industrial region or a productive sector can save consciences in distress, however it does not tackle nor solve the problem of the memories of quantities". (Olmo, 1996: p. 20)

These are not only building, machinery, product quantities, but they also have to do with people, knowledge, culture and society.

Actually, during this first phase the huge amount of urban space freed by the dismission of industries erased urgent questions: from one side there was the environmental issue and the great costs for the clearing operations and, from the other side, there was the need for recovering from these investments thanks to the increase of the land value. In Italy this period was characterized by the dismission of several industries: Falck in Milan, Italsider in Bagnoli-Napoli, Fiat-Carapelli in Novoli-Firenze, Fiat-Lingotto in 
Torino. Consequently, international calls were launched and huge estate interests emerged, which often stopped the renovation processes as in the case of Bagnoli, today still unfinished.

In the following years this phenomenon did not affect only big industries, but it became more and more diffused, widespread and pervasive. According to Istat data from 2015, in Italy the crisis has mainly interested textile, clothing, leather and accessory industries $(-5,7 \%)$, factories producing metal products ($8,1 \%)$, rubber and plastic products $(-2,1 \%)$; domestic electronic devices $(-4,3 \%)$; machineries and tools $(-$ $5 \%)$.

The comparison between the already accomplished national and international renewal successful and unsuccessful experiences, together with the changing economic scenario and the international financial crisis, favoured a change in the intervention practices, which required more consideration for the social costs of these interventions. Therefore, there was a passage from the urban renewal from the ' 90 s to the urban regeneration of the new millennium, where the change of the word (regeneration instead of renewal) represents a different consideration for all the urban, social and environmental parameters. The introduction of new city "portions" is not only a need for functionalities and forms, but also for the sustainable creation of relationships, services, meanings. Because of the lack of public fundings able to completely sustain these operational costs, the role of private business, new forms of co-design and participation of the local communities become essential. Indeed, in Italy a decree law for the co-financing of projects in brownfields is on pending approval in the Senate. We are facing a paradigmatic change: the estate based city has to be substituted with the "social and creative city" (Carta, 2014), where it is highlighted the importance of the urban recycle for the creation of more open, sustainable and equal cities; where the communities participation, also through the temporary reuse of some public spaces (as it happens in the project temporiuso.net or in the experience of BASE in Milan at ex-Ansaldo) contributes to the renovation of the meanings of places, enabling virtuous processes and new systems of production of value.

\section{The role of design in regeneration processes}

The change of perspective where design was independent from the place, to the objectivization of place as the main core of the design project, allows to talk about design as a human capability, able to change and improve places. The human factor is very important in defining the capacity of design to interact and intervene on places. Indeed, the people centered approach is particularly relevant when a regeneration process has to be planned (Villari, 2012). The importance of communities (of inhabitants, users and designers) is crucial in strategic design processes which have as objective the study and, eventually, the improvement of places.

According to this view, Ezio Manzini (2015) talks about Design as place maker because through design practices, which involve both design experts and "common" people in order to give answer to a specific problem or even to give "sense" to a specific territory, is possible to create a new ecology of places. The typology of projects which have origin by these collaborations are different and have mainly to do with design service, social innovation, and experience design. In this view, the actions put in place by designers can fill in the gap highlighted by Lefebvre (1991) where there are:

- representations of places, which are how professionals and experts (architects, engineers, urban planners) conceive the space. Lefebvre talks about top-down practices put in place by people owning institutional and political decision power; 
- representational places, which can be identified as the "artists' spaces", these are underground spaces seeking to change. Lefebvre refers to bottom-up provocative actions set up by powerless people in order to let see how places could and should be.

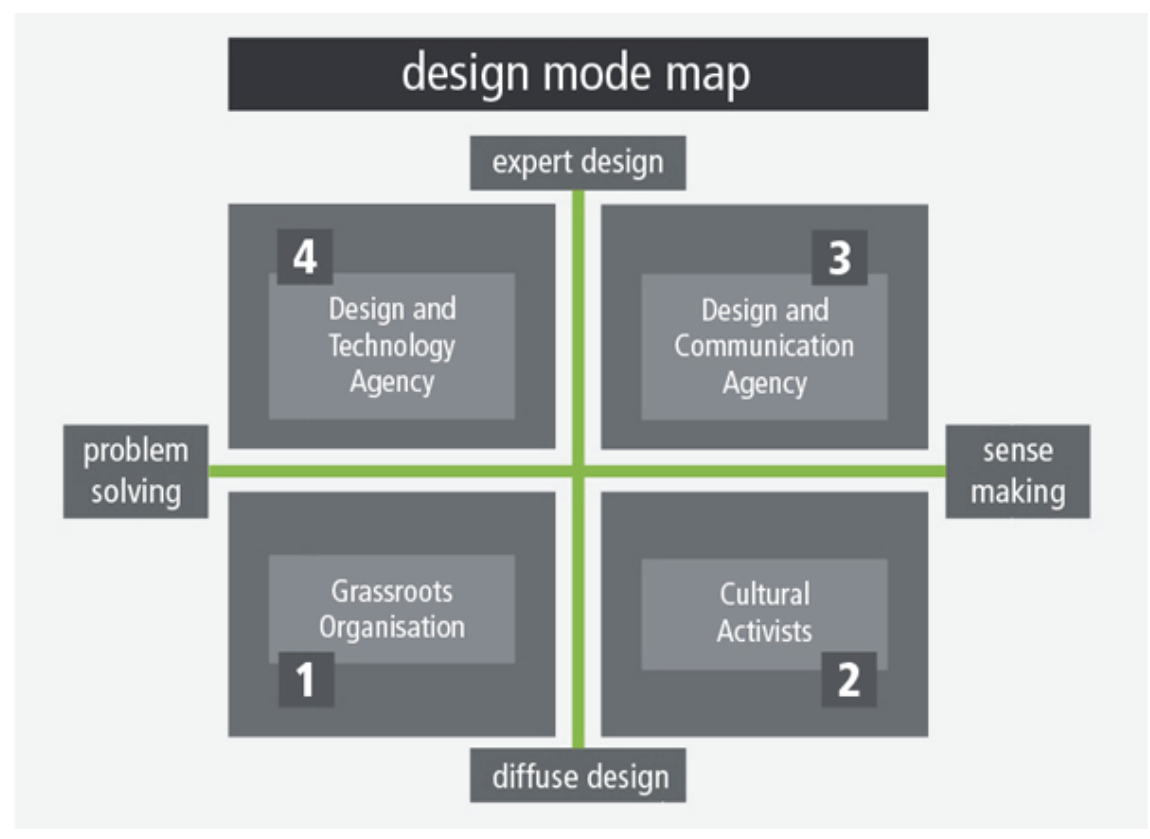

Fig. 1 The design Mode Map. Source: Ezio Manzini, (2015)

One of the purpose of this paper and also of the Research Center D4T - Design for Territories (Politecnico di Milano - Design Department) is that to systematize strategic design processes and approaches focused on places. We identified four steps of the design research process for the regeneration of places:

1. Discover and Envision: This step is focus on the identification of strategies and on methodologies to gain knowledge about a place (from the neighborhood to the national level) and then analyze this data in order to start envisioning the possibilities for involvement. This knowledge is comprised both of tangible and intangible resources, such as physical monuments or personal and collective stories and memories, all of which can be gathered both online or offline.

2. Empower: This is a pivotal moment for the Design's research focused on places. Design's goal is to uniformly connect all local activities carried out in order to empower institutions, citizens and enterprises to know, manage and take part in the culture of a specific place.

3. Communicate: Another important role that Design can play is establishing more efficient ways of communicating knowledge gathered about a place: both within the area of specific study and beyond, in meaningful way according to the given purpose of the research.

4. Re-invent and Re-produce: In this phase, specific activities take place, such as integrating service design for tourism, culture or welfare; strategic design for place and sense making, place branding or competitive position attainment; policy design for local and sustainable development; etc. 
Design owns specific capabilities useful for the valorization of territories. To the model presented above, it is possible to integrate what Francesco Zurlo called "design capabilities". In particular, the capabilities of seeing, foreseeing and let seeing (showing) can be functional to the design process for the studyresearch of the territorial system.
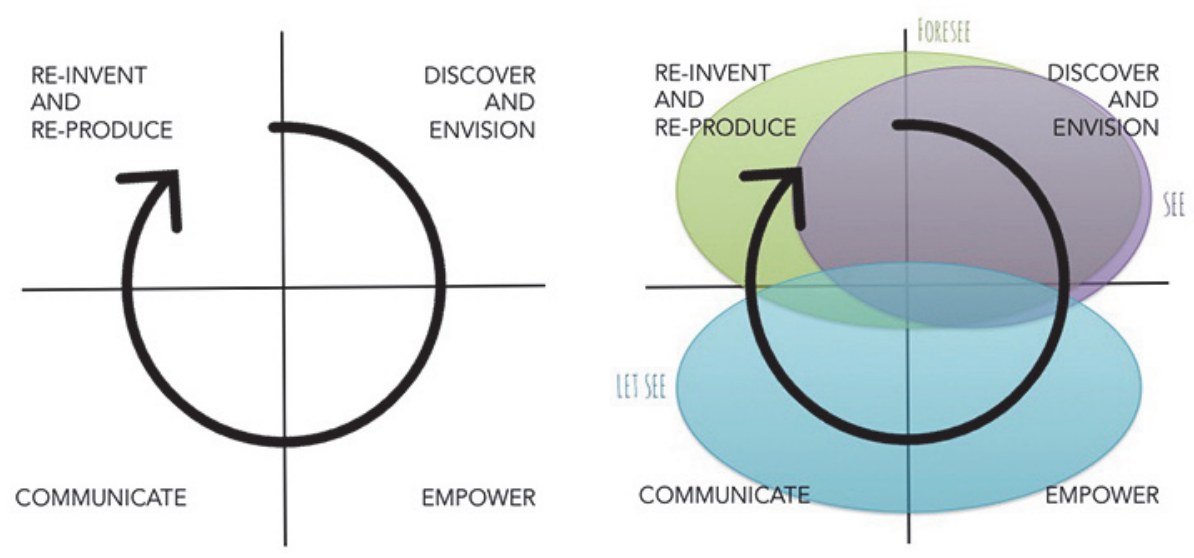

Fig.2 The strategic design process and the design capabilities

We can propose the following interpretation:

- SEE. The ability to see allows taking a critical look at the territories and sounding their physical, cultural, and social, knowledge resources, connected also to the governance system and to the contacts with the outside world. The design ability to see through its own set of methodologies, allow to read, feel and listen the territory. This capability specifically fit into the first step of the design strategic process (Discover and Envision) even if is partially present also in the Reinvention and Re-production phase.

- FORESEE. The ability to foresee go through the interpretation of the seeing action. The prevision can also be visualized and tell to discuss it with the actors from the territory, to activate co-design activities, to get closer the community to the decisional process and to create agreement. The capability to foresee, as the previous one, is present both in the first phase of the process (Discover and Envision) but it is particularly important and relevant for the fourth phase (Re-invent and Re-produce).

- LET SEE. The ability to let see (to show) allows to internally and externally communicate the territorial identity, not only through brand design and through the design of efficient communication artifacts, but also through activities which strengthen the territorial representative values. This capability is, instead, especially exploited during the "Empowerment and the Communication" phase.

In the following pages, in light of the above mentioned theories and approaches, we are going to present two different educational experiences carried out within the Master Progettare Cultura (Designing Culture) and the Higher Education Course BST-Branding the Territorial System. 


\section{Case studies}

In the following sections we are going to talk about two different case studies, where the factories crisis and their consequential dismantlement caused for sure a crisis of the identity of the city, in the case of Biella, and of a specific area, in the case of Bicocca district in Milan.

Through 2015-2016 educational experiences, we tackled some specific issues. As Bicocca is concerned the focus is tighter on the specific relationship between an art institution (Pirelli HangarBicocca) which was recently installed in this area, where the regeneration process can be considered almost finished, in terms of structural interventions. However, as we will see, this process is not really finished nor accomplished in terms of social recognizement and sense making. As Biella is concerned, the city is nowadays facing with the issue of empty spaces and loss of functionalities and meanings. The regeneration process is partially begun and it is following a different approach compared to what happened for Bicocca.

We are going to look at these two educational experiences in order to understand the design process put in place, where different places have to be taken into consideration, different timing in the regeneration process are occurring, different goals have to be accomplished.

\subsection{Working on Bicocca: creating connections}

The Bicocca area gained its identity at the beginning of XX century when heavy industries, such as Pirelli, Breda, Ansaldo, Magneti Marelli and Falck, were installed in it.

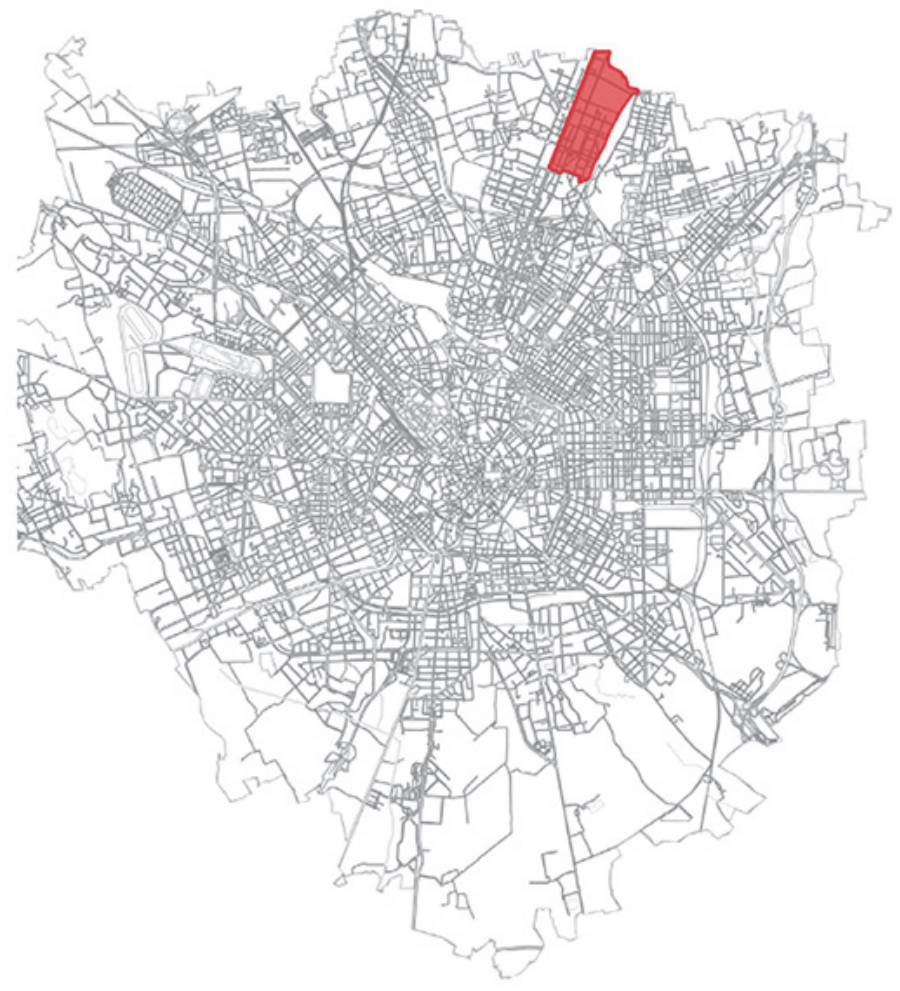


Fig. 3 Bicocca district location on the map of Milan. Source: Students work-S.Barozzi, C.Federici, V.M.Grattacaso, F.Regorda, M.Saccocci

In early ' 80 s several plants were dismissed and the production ceased. The Pirelli Group was enough forward-looking to start thinking about the reconversion of this area. Therefore, in an agreement between Pirelli SpA, the City and Provincial Governments of Milan, the Lombardy Regional Government and the Labour Unions, several experts were invited to participate in a contest to re-think the destination of this area. The regeneration process of Bicocca area begun in the ' 80 s and it was formally concluded in 2005. The Studio Gregotti \& Associati was chosen for carrying out this process in 1988. The settlement model was initially based on the idea of Bicocca as a science park for innovation; then the main goal shifted to the polycentric development of the city, where Bicocca should had become an additional and new city centre for the suburb areas of Milan. In order to reach this goal, the "Gran Bicocca Project" included the settlement of the University (1991), the CNR, the Teatro degli Arcimboldi (2001), residential units, public spaces and green areas. As it is evident, the followed strategy was that of the knowledge oriented renovation. Another physical element for this renovation was the opening of centre for contemporary art HangarBicocca in 2004 (now called Pirelli HangarBicocca). However, more recently, in 2005, with the construction of the Bicocca Village big mall, the consumption and leisure direction was taken as well.

Bicocca renewal is probably closest to what Lefebvre defined a representation of place. Indeed, apart from few visual elements, such as the cooling tower which was transformed in the conference hall of Pirelli HQ, a connection between the multiple layers composing Bicocca wasn't put in place.

"The sensation that in the place of the factory as an element governing the area and its rhythms there has arisen a foreign body that does not integrate with the rest, but which does not remain deliberately asiede either, thereby is generating a sense of fragmentation in the district." (Mugnano, Tornaghi, Vicari, 2005: 182)

As the scholars mentioned above declared, the disappearance of factories, which gave a real connective tissue to the whole area, left space a networking emptiness among the new realities installed on the territory. Nowadays, for sure, Bicocca is mainly identified with its university, even if we cannot talk about a university district, because there is mainly a functional use of the university as a place for studying and not really devoted to sociality. However, this transformation is (probably) still ongoing. At the same time, the relationship between these big institutions (the university, Pirelli HangarBicocca, the mall, Arcimboldi Theatre,...) are pretty missing. The disconnection among them goes together with the detachment between them and the old inhabitants. These new realities are "locked": it is hard to experience them from the outside and in some cases, as for Pirelli HangarBicocca, they are almost hidden and invisible from the outside.

Within the Master Designing Culture (Progettare Cultura) held by Politecnico di Milano and Università Cattolica del Sacro Cuore, during the academic year 2015-2016, the focus was on the Bicocca district and in particular on Pirelli HangarBicocca. 


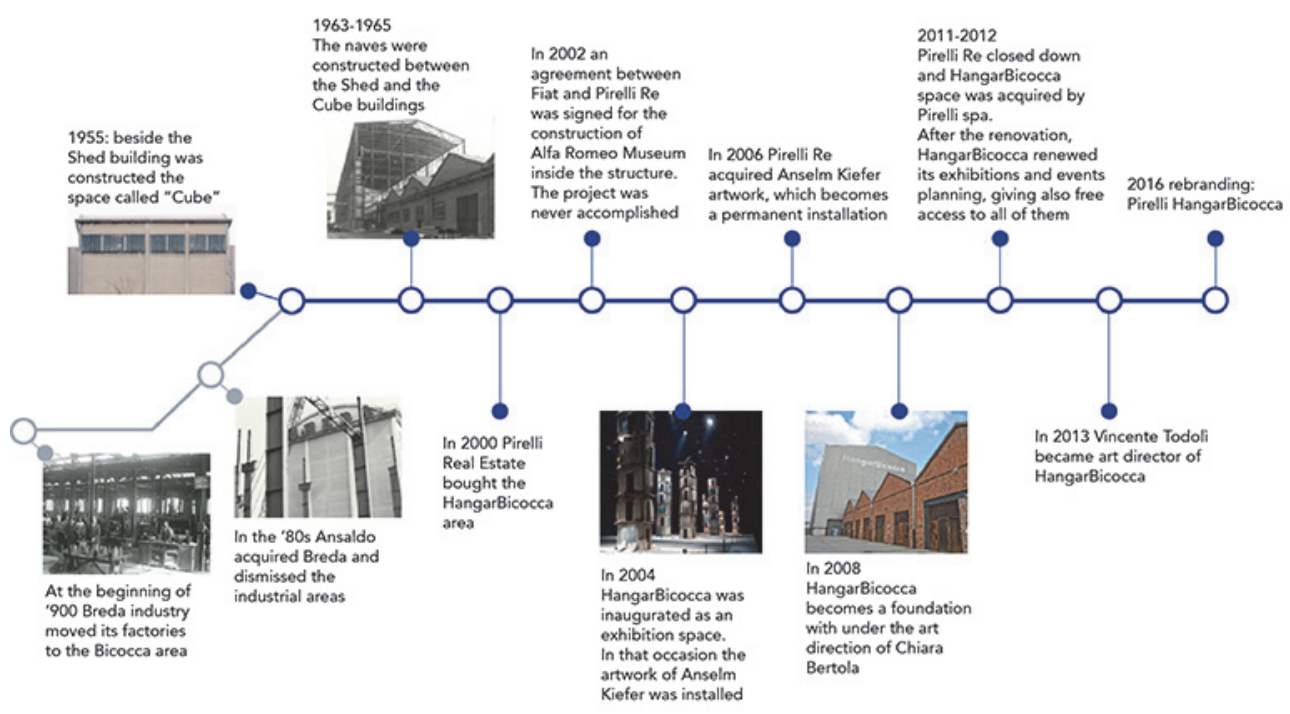

Fig. 4 Pirelli HangarBicocca born and development. Source: Students work-M.De Francesca, E.Domenichetti, V.A. Dovico, M. Fonseca

Indeed, Pirelli HangarBicocca is the customer for the project work phases of this year. The objective of the work, to be accomplished during the course, is that of reading this art institution in relationship with the neighborhood and with the young users (18-30). The final goal, indicated by Pirelli HangarBicocca, is to think and to propose design strategies in order to:

1. Improve the relationship of Pirelli HangarBicocca with the Bicocca district

2. Improve the attraction of young visitors in the cohort age 18-30

In order to do that, the students were introduced to the knowledge of both the area and the institution through frontal lessons and private meetings with the whole staff of Pirelli HangarBicocca.

The first stage of this work was mainly focused on the collection of information and data. The intermediate project work was organized splitting the class in five groups, each of which was focus on the analysis of a specific "attractor". Indeed, we identified five different territorial attractors concerning the specific target group 18-30:

- The University

- The mall Bicocca Village

- The MIL, polyfunctional space for creativity and design

- The Edificio Sedici, composed by 65 factory lofts for creative and knowledge studios and agencies

- Bars, pubs and self-managed social centers which animate Bicocca nightlife

After having developed a desk analysis about the area, the students were asked to carry out a field analysis based mainly on qualitative methods, such as observation and interviews (structured or semistructured). Each group, after having done a general analysis of the area and the client (Pirelli 
HangarBicocca) focused its attention on the young students, workers and users of the above listed attractors.

The analysis of the neighborhood returned a fragmented image of Bicocca, composed by old and new citizens, services, public spaces, etc.. In addition to that, all the groups stressed infrastructural problems which affect the district and its perception of safety, openness and welcome.

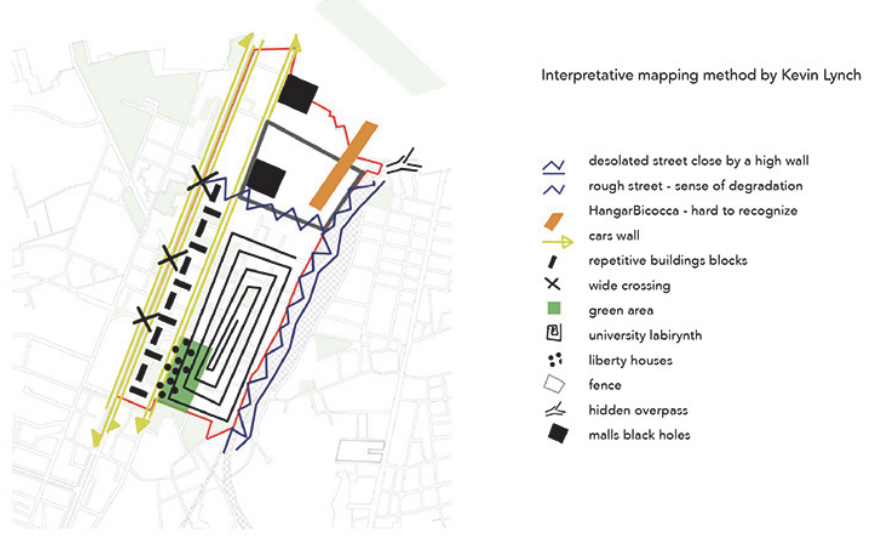

Fig. 5 Bicocca conceptual map . Source: Students work - M.De Francesca, E.Domenichetti, V.A. Dovico, M. Fonseca

From the collected interviews this spacial constraints are reflected in a small scale on Pirelli HangarBicocca.

The university students from Bicocca University (about 30), who answered to the incentive and associative question "If I tell you contemporary art what it comes into your mind?" in some cases mentioned the name of HangarBicocca. However, when asked about the institution, many of them didn't have nor knowledge or experience of this space. Some of them even associated Pirelli HangarBicocca with the nearby mall Bicocca Village. It is evident a crucial lack of knowledge of what exactly this building is and what it is about.

Some young interviewees from the "nightlife" group, declared not to be aware about the existence of this art institution which seems to have more popularity outside of the district than in the local area where it is located.

"Hangar...I know that it exists, but I don't know what it has to offer me. I didn't know that it was an exhibition space nor that there is a restaurant in it." Silvia - nightlife interview

Young people who know this art space declared that it is not particularly attractive for potential users of their same age.

"Hangar doesn't exist in my peers minds. It seems that it doesn't want to involve young people.

It is not attractive from the outside. It seems always closed and dark. Its advertising doesn't go on the channels which my colleagues and I use." Sabrina - nightlife interview

Among the young users of the mall Bicocca Village, 43 respondents out of $55(78 \%)$ had never been to Pirelli HangarBicocca; 18 of them (33\%) do not even know about its existence. 


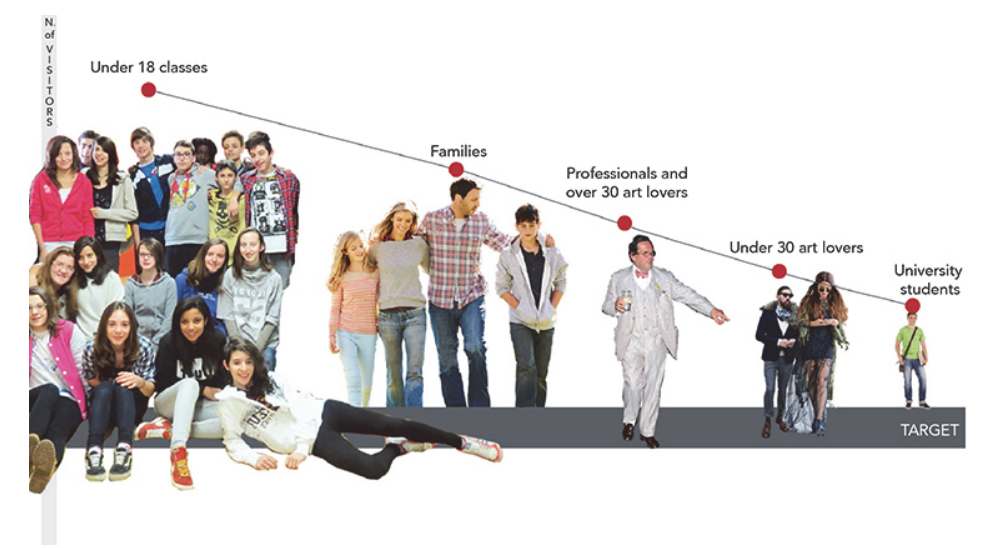

Fig. 6 Number of visitors according to the target . Source: Students work - M.De Francesca, E.Domenichetti, V.A. Dovico, M. Fonseca

In the month of June (2016) the students are going to accomplish the final project work. After a new confrontation with Pirelli HangarBicocca, also in light of the results from the intermediate pw, a need for a better communication emerged. Nowadays, Pirelli HangarBicocca is already developing some projects and actions oriented to be more open to the outside. Apart from launching a membership card to fidelize even more the already existing users, they have just run the first streetart intervention of the new program "Outside the Cube", hosting the artists OSEGEMEOS (Gustavo and Otávio Pandolfo) with their work Efêmero. It is particularly interesting the fact that the mural was inspired both by the history of Pirelli HangarBicocca building, where train locomotives were built, and by the present structure of the area, characterized by the close proximity of railway lines. Another important appointment will take place on the 27th of May: a conference titled "Education through contemporary art. New participation forms. Schools, museums and universities for an educational alliance" will take place thanks to the collaboration with the Università degli Studi di Milano Bicocca.

Since some activities open to other institutions and to the relationship with the neighborhood have already been put in place, the students will be asked to work, as already said, on the communication topic. This issue will have to be tackled from several angles, not only from an advertising point of view. The students will have to work both on the tangible and intangible levels of communication and artifacts, in relationship with the physicality of the space and with the more ephemeral, but really important, narratives about the institution, its brand and its identity.

\subsection{Working on Biella: a wider approach for a new identity}

Biella, a state capital of the Piedmont region, known for its textile production (specialized in the wool industry), was affected by the industrial crisis, which had as results the production decrease, the reduction of the average industrial dimension, and the dismission of some important textile factories (e.g. Lanifici Rivetti). 


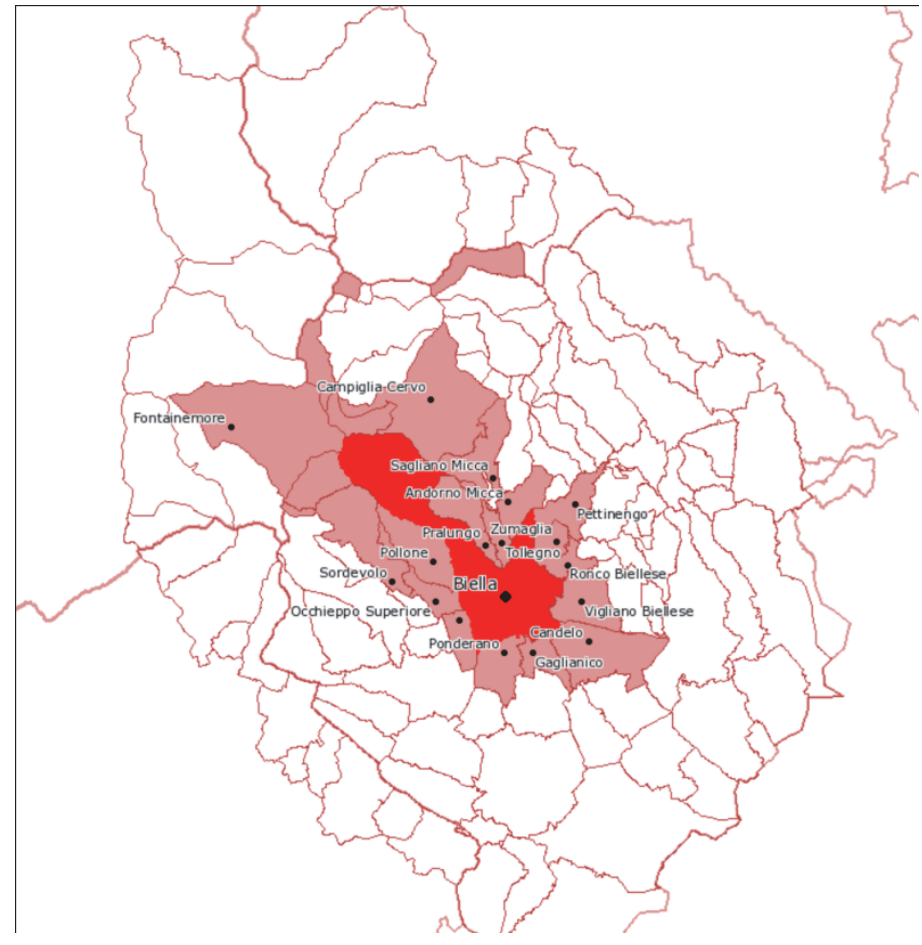

Fig. 7 Biella province. Source: comuniverso.it

However, it must be said that the textile district of Biella still exists, thanks to processes oriented towards the specialization in branches of excellence production for the high-end market sectors and the recognition of the importance of textile industries archives (Osservatorio Distretti Italiani, 2014). However, the installation of big malls at the outskirts and the displacement of the hospital, contribute to empty out the city centre.

In the past, the mono-industrial inclination, which characterized the economic development of Biella, and the closure of these places from the outside world, were strengths of this territory and really characterized its stance. Today, a deep changed scenario is forcing Biella to redefine its strategic goals also in terms of awareness and recognition from the outside, because the values of privacy and closeness are no longer useful and they are showing all their limits.

This territory has to face with big challenges because it lost its points of reference. The city has to deal with a system of empty spaces, not only physical and functional, but also of value and meaning. For this reason an evaluation of the available system of resources is needed in order to re-focus Biella objectives for growth and identity. This process, in order to be accomplished, has to be developed in light of the sense of belonging to a community, but also thanks to the collaboration and the competitive comparison with the outside world in order to renovate its own offer and value systems.

This topic was the object of interest for the activities of research and design in the VI edition (2015) of the Higher Education Course BST-Branding the Territorial System of Poli.design - Consorzio del Politecnico di Milano. The course was entirely held in Biella territory: a very interesting case study, where new initiatives in contemporary art, design and agroindustrial sectors go together with the inflection of the textile industry sector and to the empty of the production and commercial spaces. This abundance of resources was not really exploited in the past; but today these resources together with a wider openness to tourism and cultural market sectors would be the drivers for a re-thinking process. 
The goal would be that of giving resonance to the specific qualities of the place, both to the historical heritage and to the most recent business initiatives, in order to build a sense making system able to:

- drive the urban regeneration processes;

- grant a strong territorial awareness;

- $\quad$ start new market orientations, which respected people and local stakeholders;

- valorize local knowledge.

The first section of the course, focus on theoretical and methodological modules, was immediately integrated with the acquisition of knowledge about Biella, take advantage of the opportunity of being physically on the place. In this way, the role of a "directed" design, which needs to see, ear and directly interact with local actors and places of study, was reinforced. The different modules were thematize according to four focus - Arts/Heritage/Landscape, Food, Design, Fashion/Textile - integrating theoretical lessons, focused visits and seminars, these last organized by the Associazione 015 Biella, partner of the project.

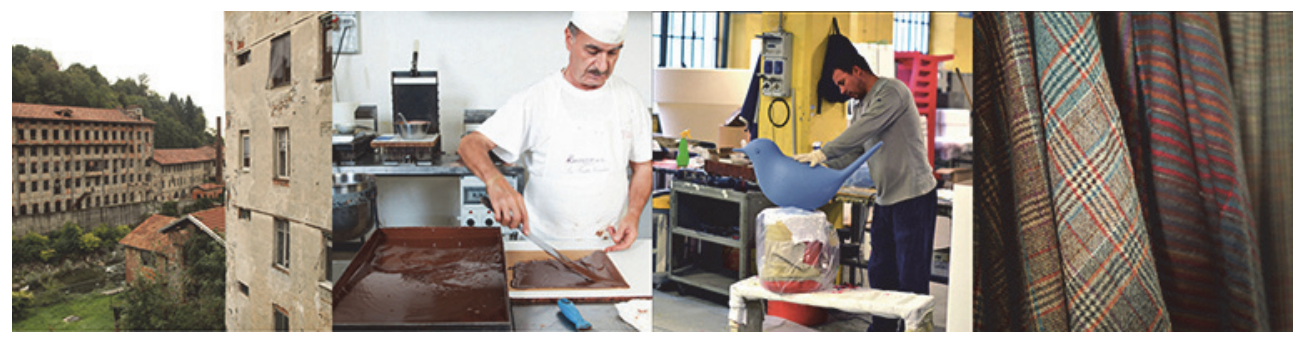

Fig. 8 The territorial analysis: Arts/Heritage/Landscape, Food, Design, Fashion/Textile. Photos by C.Sedini and C.Iemmolo

The week of the intensive project work treasured the methodological lessons and the fact-finding experiences of the previous modules to arrive to the synthesis of five project scenarios developed for different thematic fields: water, events, shopping, sustainability, make. These topics could had to be interpreted both as distinct hypothesis and as an interconnected system of actions to be developed in the mid-long term. Scenarios hinged on data and information gathered thanks to the analysis and the critical interpretation of the territory, thanks to the confrontation with the local actors, thanks to the identification of values and sleepy or forgotten potentialities. The students developed all site specific proposals which hopefully could start a dialogue among institutions, entrepreneurs and inhabitants in order to elaborate some share hypothesis of action. The next step is a new edition of the course in order to go on with the dialogue with local institutions and to deepen the concepts developed in the first year.

Fig. 9 Five concepts for Biella: place identity, storytelling and strategic plan of intervention. Source: Students projects logos
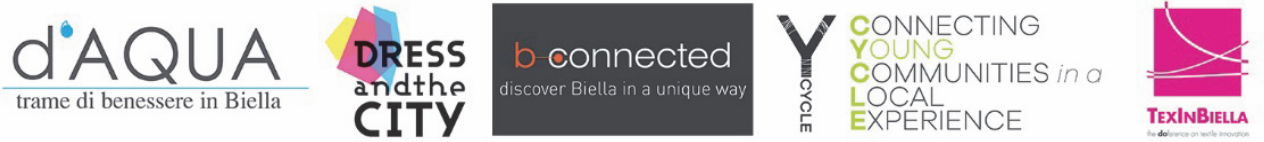


\section{Conclusion}

In 2003, Roditi wrote in its chapter Milano-Bicocca: da area industriale a centro urbano "nuovo" (Milano-Bicocca: from industrial area to "new" urban centre) that a walk by the streets of Bicocca, especially in the nighttime, is able to give a sense of disorientation and placeness, probably due to the difficulty of giving a specific meaning to the new urban shapes. The shapes mentioned by Roditi can be seen as the building which characterized that area: the University, the big mall, Arcimboldi Theatre and Pirelli HangarBicocca, as well. Some of these spaces conserved the old structures which were filled in with new contents, others are completely new. However all of them are closed systems, both in terms of their strongly fenced physicality and in terms of their knowable and permeable identity. Today the sense making of Bicocca has surely improved, even if it is mainly connected to the presence of university students and workers (Pettenati, 2012).

Biella case study is particularly interesting because the industrial crisis influenced first of all a redefinition of the textile sector. After the dismission of several industries, private foundations, such as Fondazione Pistoletto and Fondazione Banca Sella, appointed themselves as promoters for the reconversion and the regeneration of several abandoned spaces, using culture and art as main drivers. Differently from Bicocca case, here still are several empty spaces to be reconverted, meanings to be defined and economies to be rethought. Another difference is the diffusion and the parcelization of areas where these interventions are needed; indeed these spaces are scattered in the whole city. Since this is an ongoing process, there is the possibility to follow an integrated process which acted both on hard and soft elements of places and with participatory models, with the multiple actors involved.

As we have seen in the previous pages, design can be place making (Manzini, 2015) thanks to the strategies and processes which involve both design experts and "common" people, as for example citizens, in order to give answer to a specific territorial issue or even to give "sense" to a place. Design can play different roles. In cases, such as the Bicocca district, where the renovation process is already accomplished in terms of infrastructures (hard factors) design is able to rejoin the fragmented pieces resulting from the renovation. This goal can be accomplished going from the "Discover and Envision" step of the strategic design process, where designers (experts or not) see the territory, its tangible and intangible resources, to the "Empower" and "Communication" steps. Indeed, it is in these phases of the process that designers let see to the actors involved their potentialities and those of the place. The results expected from this work, which is specifically focus on the artspace Pirelli HangarBicocca, are those of:

- make visible the richness of the offer that the various cultural actors generate in this area

- envision innovative connections among the different local actors

- co-produce and share the knowledge generated inside these cultural institutions.

In cases, such as the city of Biella, where the regeneration process is at its beginning, design can help in looking forward, identifying common purposes of the different communities of actors. The whole society has to be involved: citizens, entrepreneurs, private foundations and businesses, trade associations, cultural and governmental institutions. In order to avoid identity and sense making problems, due to parcelized and isolated (in the meaning of disconnected) interventions to the space, it is important to combine hard and infrastructural intervention with other soft levers, which are often used in design strategies. Also in this case the first important step is "Discover and Envision" and after going through "Empower" and "Communication" phases specifically oriented for the actors involved in the design process, the crucial step of this process is the Re-invention and Re-production phase. Indeed, it is here that designers start to really foresee the possible paths to follow. 


\section{References}

CARTA M. (2014). "Re-cycling urbanism” in On/Off Magazine. <https://onnoffmagazine.com/2014/02/10/recycling-urbanism-indizi-e-orizzonti/>

LEFEBVRE H. (1991). The production of space. Oxford: Blackwell.

MANZINI E. (2015). Design, when everybody designs: An introduction to design for social innovation. Cambridge, Massachussetts: MIT Press.

MUGNANO S., TORNAGHI C., VICARI HADDOCK S. (2005). "New visions of the territory: urban renewal and new public spaces", in Dell'Agnese E. La Bicocca e il suo territorio. Memoria e progetto. Milano: Skira.

OLMO C. (1996). "Le molte memorie di una città industriale", in La trasformazione delle aree dismesse nella esperienza europea, Bollettino del Dip. di Progettazione Urbana, Napoli, n.2/1996, p.20.

PARENTE M. (2012). “Affirming place identities” in Ottagono n.249, pp. 58-65.

PARENTE M. (2002). La conoscenza scientifica e tecnologica. I luoghi, le memorie, le tracce, Quaderni del design 2, Napoli: CUEN.

PETTENATI G. (2012). "La Bicocca: centro per la metropoli o quartiere per la città?” in Archivio di studi urbani e regionali, vol.104, p. 91-108.

RODITI G. (2003). "Milano-Bicocca: da area industriale a centro urbano "nuovo"”, in LEONE U. Aree dismesse e verde urbano. Nuovi paesaggi in Italia. Bologna: Patron.

RUBINO G. (1996). "Principio della conservazione", in La trasformazione delle aree dismesse nella esperienza europea, Bollettino del Dip. di Progettazione Urbana, Napoli, n.2/1996, p.119.

SECCHI B., "Un ampliamento dello sguardo", in RASSEGNA n.42/1990, pp.61-62.

VILLARI B. (2012). Design per il territorio: un approccio community centred. Milano: FrancoAngeli.

DECREE

LAW

N.1836

<https://www.senato.it/japp/bgt/showdoc/17/DDLPRES/926036/index.html?part=ddlpres_ddlpres1-relpres_relpres1>

OSSERVATORIO DISTRETTI ITALIANI, $2014<\mathrm{http}$ //www.osservatoriodistretti.org/node/26/distretto-industrialetessile-abbigliamento-biella> 